\title{
Hacia un modelo de rúbricas para la evaluación de aprendizajes en productos audiovisuales, en función del perfil de egreso de la Carrera de Comunicación Audiovisual y las especialidades de Cine y Televisión de la Universidad UNIACC
}

doi: $10.33264 /$ rpa.201802-11

Dr. Christian Reyes Gavilán

Dr. Alexander Pszczolkowski Parraguez Javier Muñoz Percherón

\section{Resumen}

El estudio se focaliza en torno a un componente crucial en los procesos formativos: la evaluación, sus prácticas e instrumentos. Se desarrolla un marco teórico acerca del Modelo Educativo de Universidad UNIACC, el respectivo perfil de egreso de las especialidades de Cine y TV de la Escuela de Comunicación Audiovisual, y el enfoque denominado Evaluación para el Aprendizaje (EpA) como base de una reflexión crítica y optimización de los criterios, escenarios e instrumentos (rúbricas) referidos a evaluar la realización de piezas audiovisuales. Se trata de una investigación de enfoque cualitativo que, mediante entrevistas semiestructuradas a docentes, expertos en la materia y grupos de discusión con estudiantes, recoge datos que permitan fundamentar un modelo conceptual y procedimental focalizado en la resignificación del proceso evaluativo hacia la construcción de rúbricas con enfoque holístico que propone el modelo EpA. Conclusivamente, se discute sobre la necesidad de repensar el proceso evaluativo, en particular en este tipo de carreras, donde buena parte de los procesos y productos suponen no solo una apropiación técnica, sino además el ejercicio de la creatividad estética y el desarrollo artístico.

Palabras clave: Evaluación para el Aprendizaje (EpA), modelo educativo, perfil de egreso, aprendizaje significativo, comunicación audiovisual, escenarios de evaluación, rúbrica holística.

\section{Abstract}

The study focuses on a crucial component in the training processes: assessment, its practices and instruments. It provides a theoretical framework about the Educational Model of UNIACC University and the profile of graduation of Cinema and Television 
majors of the School of Audiovisual Communication. Additionally, the Assessment for Learning (EpA in Spanish)* approach, as a basis for critical reflection and optimization of the criteria, scenarios and instruments (rubrics) required for assessing the making of audiovisual pieces. This is a qualitative research that, through semi-structured interviews with teachers, experts in the subject and discussion groups with students, collects data to support a conceptual and procedural model focused on the resignification of the assessment process towards the construction of rubrics with holistic approach proposed by the EpA model. Conclusively, we discuss the need to rethink the assessment process, particularly in this type of degrees, where a good part of the processes and products involve not only a technical appropriation, but also the exercise of aesthetic creativity and artistic development.

Keywords: Assessment for Learning (EpA), educational model, profile of graduation, significant learning, audiovisual communication, assessment scenarios, holistic rubrics.

\section{Introducción}

La investigación se enmarca en el área de la educación y se adscribe a la formación continua como un elemento deontológico basal del ejercicio de la docencia. En particular, el estudio se orienta en la búsqueda de mejores prácticas de evaluación, las cuales permitan optimizar el proceso de obtener información relevante respecto al proceso de aprendizaje (especialmente el que se manifiesta en productos audiovisuales), y viabilizar así el logro de aprendizajes significativos por parte de las y los estudiantes de la Escuela de Comunicación Audiovisual de la Universidad UNIACC, conforme al Modelo Educativo institucional que, por lo mismo, también es objeto de análisis en este estudio.

La metodología que se ha utilizado es de tipo cualitativa. Se busca rescatar los aspectos emergentes con un enfoque constructivista, desde su propio marco de referencia (Krause, 1995; Pérez Serrano, 1994; Taylor y Bogdan, 1992). Se realizó un análisis sistemático de los aspectos fundamentales que se declaran en el Modelo Educativo de la Universidad UNIACC y en el perfil de egreso de las especialidades de cine y televisión de la carrera de Comunicación Audiovisual de la misma casa de estudios. Se aplicaron, paralelamente, encuestas a docentes de las especialidades mencionadas y se desarrollaron grupos de discusión con estudiantes de ambas especialidades. Asimismo, se llevaron a cabo entrevistas semiestructuradas: a la directora de la Escuela y a una experta en el ámbito de la evaluación educacional, específicamente en Evaluación para el Aprendizaje, dado que este enfoque se 
presenta como una vía plausible para la resignificación de los procesos evaluativos aplicados en la carrera.

\section{Marco teórico}

\section{Modelo educativo.}

La Universidad de Artes, Ciencias y Comunicación, hoy más conocida por su acrónimo UNIACC, imparte la carrera de Comunicación Audiovisual prácticamente desde su fundación en 1981. Dicha carrera, en la actualidad, cuenta con tres especialidades: cine, televisión y guiones para cine y televisión. Dada la semejanza dialógica entre sus perfiles de egreso y los efectos de ello para los procesos de evaluación de los aprendizajes, la investigación se aboca únicamente a las dos primeras especialidades mencionadas: cine y televisión.

La razón de ser como institución y, a la vez, lo que ofrece a la sociedad a través de su modelo educativo, permiten avizorar cómo UNIACC entiende su misión. Al respecto, explícitamente declara:

Formar integralmente a distintas personas, independientemente de su edad, condición social y ubicación geográfica, mediante una educación terciaria de calidad que reconoce al sujeto como una totalidad -integral e integrado en un contexto social determinado- habilitándolo para aprender a: aprender, hacer, ser y convivir, tal que se caracterice por su conciencia y compromiso con el bien público y con su propio desarrollo. (UNIACC, 2015, pp. 2 y 3).

De la enunciada misión, destacan las precisiones "habilitadoras" que se nombran: aprender a aprender, a hacer, a ser y a convivir, en perspectiva de tomar conciencia y comprometerse con el "bien público" y con "su propio desarrollo". Es interesante notar que el orden enunciativo de las perspectivas señaladas antepone el "bien público" al "desarrollo personal", aunque desde luego la intención comunicativa parece relevar, al menos la simultaneidad de ambos procesos.

En cuanto a su visión, declara UNIACC:

Ser una Universidad reconocida por su oferta de enseñanza terciaria de calidad en sus distintas modalidades de enseñanza y aprendizaje -Presencial, Semipresencial y No presencial (full online) -, de modo que sus programas faciliten el acceso a la formación superior a todos quienes deseen formarse en las áreas artísticas, de las ciencias sociales y de administración, con énfasis en la comunicación, uso de tecnologías e innovación. (UNIACC, 2015, p. 3). 
Así, la visión queda enunciada de manera que se considera como eje el "reconocimiento" centrado en la "calidad" y la matrícula abierta (esto último, desde luego, no puede conceptualmente confundirse con “inclusión”). En consecuencia, no se percibe con claridad la relación dialógica necesaria y esperable de la misión-visión institucional y esto, eventualmente, podría repercutir en los componentes sustantivos para este estudio: modelo educativo y perfiles de egreso.

Sobre el primero, sostiene la documentación oficial de la universidad UNIACC (las mayúsculas y negritas están en la fuente):

Nuestro Modelo Educativo emplaza sus metas curriculares en la consecución de Aprendizajes Esperados con un enfoque hacia la Creación-Transformación, desde un sujeto que está inserto en un contexto sociocultural, pero que a la vez tiene la capacidad, responsabilidad y compromiso de transformarlo, en virtud del bienestar colectivo (UNIACC, 2016, p.5).

Se aprecia, entonces, un alineamiento de sentido bastante evidente con la "misión" antes detallada: desde luego, los "aprendizajes esperados" no ofrecen novedad alguna en este ámbito en cuanto tales, pero sí lo hace el "enfoque" que, en este caso, apunta a la "Creación-Transformación”. ¿Qué se entiende por “creación”? Ni antes ni después, el modelo en comento aborda el concepto con el detenimiento que sería esperable para una noción que — nada menos — sitúa el sentido de los "aprendizajes esperados". Lo mismo cabe decir de la "transformación" aludida de modo yuxtapuesto con creación. Sin embargo, cuando en el documento sobre el modelo educativo institucional se aborda el "ciclo pedagógico", coherentemente se refuerza que tal ciclo concluye en la "creación-transformación”, a cuyo respecto se señala:

La demostración de la apropiación efectiva y la resignificación activa del nuevo conocimiento es que el estudiante tiene la posibilidad de usarlo para la construcción de nuevo conocimiento, integrarlo en un contexto específico y comunicarlo a otros, ofreciendo nuevos significados al colectivo. Con base en lo anterior, el estudiante es capaz de transformar y construir y contribuir al desarrollo de la realidad cultural y de su disciplina. (UNIACC, 2016, p.7).

Así, “creación” parece implicar (a) "construcción de nuevo conocimiento”, (b) su integración a un contexto y (c) su difusión, en tanto que "transformar" funciona copulativamente con (a) "construir" y (b) "contribuir" a la cultura y a su disciplina (cabría preguntarse si acaso la disciplina no forma parte de la realidad cultural y, en ese mismo orden de necesarias aclaraciones, considerando lo plurívoco del concepto de "cultura", qué se está entendiendo por él). Llama la atención, además, la calificación de "nuevo" para el conocimiento que se espera que evidencie la finalidad 
“creativa” de la enseñanza. ¿Es posible tal "novedad creativa” a estas alturas de la historia? Lethem (2008) sostiene: "Hallar la voz personal no es solo vaciarse y purificarse de palabras de otros, sino adoptar y acoger filiaciones, comunidades y discursos" (p. 16). Una tensión epistemológica semejante puede decirse que se manifiesta en la manera en que parece entenderse "transformar" copulativamente con “crear". ¿Por qué se reduce a "construir" y “contribuir”? ¿Construir sobre lo ya existente, aceptándolo de manera acrítica? ¿Cómo se contribuye a la cultura y a su disciplina? ¿Solo construyendo? No dirían lo mismo la pléyade de intelectuales, artistas, líderes y lideresas en todos los ámbitos del quehacer humano que han roto los moldes sociales, culturales, científicos, estéticos, políticos para fundar o recrear teorías y praxis que nos desafían sin tregua en la construcción vital comunitaria e individual.

Finalmente, el documento se despliega en torno al “Modelo Evaluativo", señalando que la evaluación es entendida desde dos fundamentos. En primer término, "Como el conjunto de estrategias e instrumentos que permiten la valorización del nivel de logro de los aprendizajes" (UNIACC, 2016, p. 9). Es decir, la evaluación trasciende la mera medición de logros, y se orienta hacia la valorización, lo que, como veremos más adelante en este informe, significaría adoptar un enfoque que, efectivamente, se oriente a esa "valorización".

En segundo lugar, la evaluación se entiende "Como un dispositivo que facilita y orienta, desde el análisis de sus resultados, la autorregulación (estudiante) y regulación (docente) de la metodología empleada para el logro de los aprendizajes." (UNIACC, 2016, p. 9). Se trata, entonces, de un mecanismo u organización que se instala para llevar a cabo el "proceso evaluativo", considerando las que el modelo llama "evidencias deseables" (UNIACC, 2016, p. 10). Estas corresponden, precisa el mismo documento recién citado, a "acciones observables que cumplen con criterios de realización que la hacen pertinente y atingente en relación a (sic) los objetivos de la asignatura." (p. 10).

El modelo, en suma, no obstante que declara trascender la medición, incurre sin embargo en al menos dos principios discutibles desde la perspectiva de coherencia con la noción de "aprendizaje significativo":

a) La evaluación como "dispositivo" que la instaura (al menos declarativamente) desacoplada del proceso de aprendizaje-enseñanza.

b) El origen completamente exógeno de todos los ámbitos que la implican. Es decir, ¿cómo se hace cargo la evaluación de la participación crítica y coconstructora de los aprendizajes que se espera de las y los estudiantes? 


\section{Perfiles de egreso}

Una de las herramientas fundamentales para trazar la ruta educativa cuando se habla de carreras o grados, es el perfil de egreso. Esto es, la declaración donde "se conjuga el tipo de formación que se quiere entregar (disciplina, profesión, nivel) y a quién se pretende formar (características de los estudiantes admitidos)." (Lemaitre, s.f., p. 1). Dicho perfil se manifiesta en una declaración explícita y pública de los fines formativos (conceptos, actitudes, comportamientos, destrezas y juicios) que la malla curricular de cada carrera alienta como finalidades en común para sus estudiantes. En consecuencia, esos fines debieran, a su vez, permear la totalidad de los componentes didácticos de cada asignatura de la carrera, incluyendo de manera muy relevante, los procesos evaluativos.

Lemaitre (s.f.) precisa que los perfiles de egreso se definen considerando tres desafíos: la pertinencia, la equidad y la formación a lo largo de la vida.

- Respecto al desafío de la pertinencia, se refiere a las capacidades que las y los egresados van a necesitar de aquí en un futuro.

- El desafío de la equidad se refiere a la gran cantidad de estudiantes que ahora tienen acceso a la educación superior, pero que, por lo mismo, exigen hacerse cargo de esa variedad. Es por eso por lo que este desafío necesita la compensación de las diferencias de entrada.

- Finalmente, el desafío de la formación a lo largo de la vida considera la premisa de que el perfil de egreso estaba diseñado para que la formación se centrara en un trabajo, en la dimensión laboral/profesional como eje de la existencia post universidad. Sin embargo, el mundo actual es muy claro en componentes que tensionan esa unidimensionalidad: la rigidez del pasado se ha convertido en la liquidez del presente y futuro; por ende, las competencias se deben orientar a hacerse cargo del desarrollo pluridimensional de cada estudiante. Como diría Edgar Morin, ir desde el paradigma de la simplicidad (principios de disyunción y reducción) al de la complejidad (principios dialógico, hologramático, recursivo) (2011).

UNIACC lo define a base de dos conceptos claves: aprendizajes esperados y saberes. A continuación, se muestran dos tablas que manifiestan los "aprendizajes esperados" para la especialidad de televisión, y luego para la especialidad de cine. Las tablas 1 y 2 que siguen exponen el desglose de los aprendizajes esperados para las dos especialidades objetos de este estudio. 
Tabla 1. Aprendizajes esperados especialidad televisión.

\begin{tabular}{|c|c|c|c|}
\hline Ámbito/Área & $\begin{array}{l}\text { ÁREA DE FORMACIÓN } \\
\text { DISCIPLINAR }\end{array}$ & $\begin{array}{l}\text { ÁREA FORMACIÓN } \\
\text { PROFESIONAL }\end{array}$ & $\begin{array}{l}\text { ÁREA DE FORMACIÓN } \\
\text { GENERAL }\end{array}$ \\
\hline $\begin{array}{l}\text { Creación } \\
\text { Audiovisual }\end{array}$ & $\begin{array}{l}\text { Domina el mecanismo de } \\
\text { la creación audiovisual, } \\
\text { tanto en sus elementos } \\
\text { técnicos como en el } \\
\text { razonamiento de cada } \\
\text { operación. }\end{array}$ & $\begin{array}{l}\text { Crea, escribe, dirige, } \\
\text { produce, post produce y } \\
\text { gestiona proyectos } \\
\text { audiovisuales para } \\
\text { diversos formatos y } \\
\text { soportes. }\end{array}$ & \\
\hline $\begin{array}{l}\text { Producción } \\
\text { Audiovisual }\end{array}$ & $\begin{array}{l}\text { Conoce, identifica y } \\
\text { comprende } \\
\text { herramientas y labores } \\
\text { ligadas a la producción, } \\
\text { desarrollo y ejecución de } \\
\text { proyectos audiovisuales } \\
\text { profesionales. }\end{array}$ & $\begin{array}{l}\text { Pre produce, produce y } \\
\text { post produce piezas } \\
\text { audiovisuales de ficción, } \\
\text { prensa y entretención con } \\
\text { vocación de masividad. } \\
\text { Complementa su quehacer } \\
\text { profesional con un fuerte } \\
\text { acervo en el área } \\
\text { tecnológica y manejo de } \\
\text { equipamiento específico } \\
\text { de su profesión. }\end{array}$ & \\
\hline $\begin{array}{l}\text { Sello } \\
\text { Institucional }\end{array}$ & & $\begin{array}{l}\text { Identifica e interpreta la } \\
\text { relación existente y en } \\
\text { permanente actualización } \\
\text { de las artes } \\
\text { contemporáneas chilenas, } \\
\text { sobre la base de la } \\
\text { comprensión e integración } \\
\text { inmaterial de diferentes } \\
\text { disciplinas artísticas. }\end{array}$ & $\begin{array}{l}\text { Concibe la profesión como } \\
\text { propuesta de } \\
\text { comunicación e } \\
\text { interacción con otros, a } \\
\text { partir de la comprensión } \\
\text { de las teorías de la } \\
\text { comunicación, por tanto, } \\
\text { comunica y expresa ideas } \\
\text { de forma efectiva. Al } \\
\text { tiempo, orienta } \\
\text { éticamente la aplicación de } \\
\text { saberes disciplinares y } \\
\text { profesionales sobre la } \\
\text { base de actitudes y } \\
\text { capacidades prácticas } \\
\text { fundamentales de } \\
\text { autonomía intelectual y } \\
\text { moral, inclusión de las } \\
\text { diversas formas en que se } \\
\text { expresa la cultura, } \\
\text { integridad en sus } \\
\text { decisiones y compromiso } \\
\text { con su desarrollo personal } \\
\text { y el de la sociedad. }\end{array}$ \\
\hline
\end{tabular}

Fuente: Elaboración propia, a partir de uniacc.cl (2018). 
Tabla 2. Aprendizajes esperados especialidad cine.

\begin{tabular}{|c|c|c|c|}
\hline Ámbito/Área & $\begin{array}{l}\text { ÁREA DE FORMACIÓN } \\
\text { DISCIPLINAR }\end{array}$ & $\begin{array}{l}\text { ÁREA FORMACIÓN } \\
\text { PROFESIONAL }\end{array}$ & $\begin{array}{l}\text { ÁREA DE FORMACIÓN } \\
\text { GENERAL }\end{array}$ \\
\hline $\begin{array}{l}\text { Creación } \\
\text { Audiovisual }\end{array}$ & $\begin{array}{l}\text { Domina el mecanismo de la } \\
\text { creación audiovisual, tanto } \\
\text { en sus elementos técnicos } \\
\text { como en el razonamiento } \\
\text { de cada operación. }\end{array}$ & $\begin{array}{l}\text { Crea, escribe, dirige, } \\
\text { produce, post produce y } \\
\text { gestiona proyectos } \\
\text { audiovisuales para diversos } \\
\text { formatos y soportes. }\end{array}$ & \\
\hline $\begin{array}{l}\text { Realización } \\
\text { cinematográfica }\end{array}$ & $\begin{array}{l}\text { Identifica, comprende, e } \\
\text { interpreta las labores } \\
\text { propias de su área de } \\
\text { especialización en } \\
\text { preproducción, producción } \\
\text { y post producción } \\
\text { cinematográfica. }\end{array}$ & $\begin{array}{l}\text { Pre produce, produce y } \\
\text { post produce piezas } \\
\text { audiovisuales tanto de } \\
\text { ficción, como no ficción, en } \\
\text { ámbitos artísticos y } \\
\text { comerciales. Complementa } \\
\text { su quehacer profesional con } \\
\text { un fuerte acervo en el área } \\
\text { tecnológica y de la } \\
\text { realización propiamente tal, } \\
\text { donde domina las áreas de } \\
\text { dirección de actores, arte y } \\
\text { fotografía. }\end{array}$ & \\
\hline $\begin{array}{l}\text { Sello } \\
\text { Institucional }\end{array}$ & & $\begin{array}{l}\text { Identifica e interpreta la } \\
\text { relación existente y en } \\
\text { permanente actualización } \\
\text { de las artes } \\
\text { contemporáneas chilenas, } \\
\text { sobre la base de la } \\
\text { comprensión e integración } \\
\text { inmaterial de diferentes } \\
\text { disciplinas artísticas. }\end{array}$ & $\begin{array}{l}\text { Concibe la profesión como } \\
\text { propuesta de comunicación } \\
\text { e interacción con otros, a } \\
\text { partir de la comprensión de } \\
\text { las teorías de la } \\
\text { comunicación, por tanto, } \\
\text { comunica y expresa ideas } \\
\text { de forma efectiva. Al } \\
\text { tiempo, orienta éticamente } \\
\text { la aplicación de saberes } \\
\text { disciplinares y profesionales } \\
\text { sobre la base de actitudes y } \\
\text { capacidades prácticas } \\
\text { fundamentales de } \\
\text { autonomía intelectual y } \\
\text { moral, inclusión de las } \\
\text { diversas formas en que se } \\
\text { expresa la cultura, } \\
\text { integridad en sus } \\
\text { decisiones y compromiso } \\
\text { con su desarrollo personal y } \\
\text { el de la sociedad. }\end{array}$ \\
\hline
\end{tabular}

Fuente: Elaboración propia, a partir de uniacc.cl (2018).

Como se puede apreciar en la Tabla 1, la primera columna contiene tres conceptos que abarcan las unidades generales de aprendizajes para la especialidad. La "creación audiovisual" tiene relación con la creatividad del estudiante y cómo utiliza las herramientas audiovisuales para crear contenidos. La "producción audiovisual" se refiere a la capacidad de gestión de proyectos, mientras que el "sello institucional" es lo que diferencia a UNIACC del resto de los establecimientos educativos que imparten la misma carrera. 
Por su parte, se aprecia en la tabla 2 que la única diferencia con la especialidad de televisión es la "realización cinematográfica", que consiste en el aprendizaje del lenguaje cinematográfico y su uso para la creación y producción de piezas audiovisuales que contengan dichos esquemas propios del séptimo arte.

Estos ámbitos del aprendizaje se expresan en diferentes áreas de la carrera, que corresponden a las columnas dos, tres y cuatro de cada tabla, a saber: "Área de formación disciplinar", "Área de formación profesional” y finalmente el "Área de formación general”. La primera tiene relación con la formación y los aprendizajes que se desarrollarán durante el lapso de la carrera. La segunda son los aprendizajes significativos con los cuales contará el/la profesional para enfrentarse al mundo laboral. El último se refiere al enfoque valórico que se le ha dado a la carrera, tales como las perspectivas éticas o el trabajo en equipo.

Los saberes que define UNIACC, como horizonte de aprendizajes que se aspira a que desarrolle quien estudia en ambas especialidades, son de tres tipos: conceptuales, procedimentales y actitudinales.

El primero incluye las bases teóricas o nocionales que las y los estudiantes han aprendido, y que son la base de las acciones en su labor profesional, o bien, de procesos de formación continua posterior. En la especialidad de cine, estos saberes se explicitan en la figura 1, a partir de la documentación oficial de UNIACC tenida a la vista:

Figura 1. Saberes conceptuales especialidad de cine.

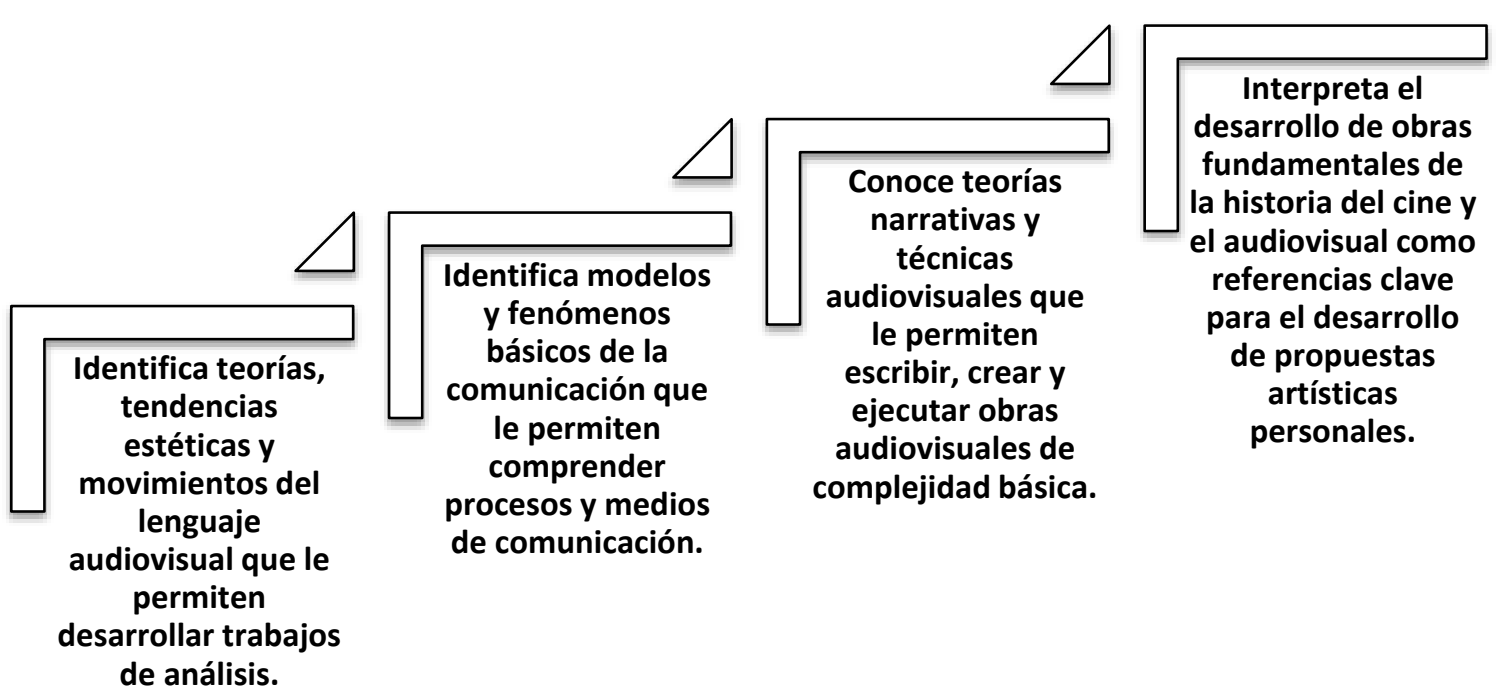

Fuente: Elaboración propia, a partir de uniacc.cl (2018). 
En el caso de la especialidad de televisión, estos saberes corresponden a los que se explicitan en la figura 2.

Figura 2. Saberes conceptuales especialidad de televisión.

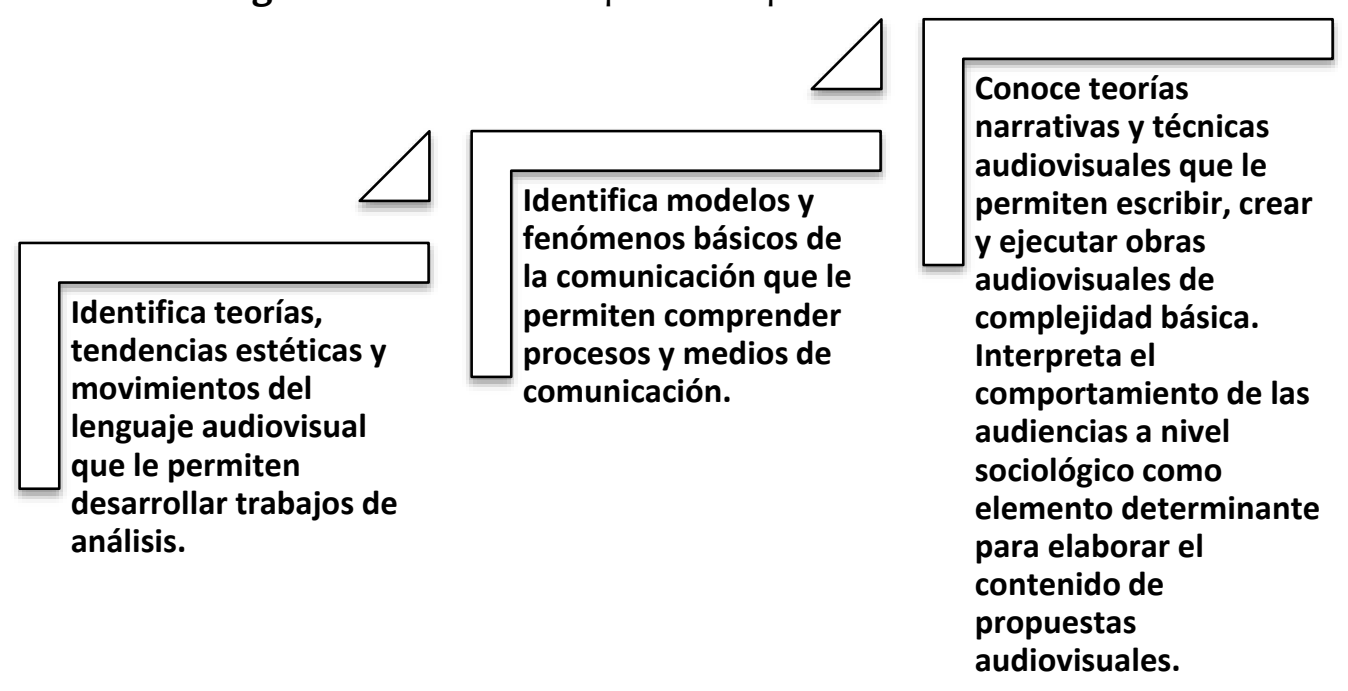

Fuente: Elaboración propia, a partir de uniacc.cl (2018).

El segundo saber abarca cómo los profesionales complementan el saber teórico conceptual con técnicas de realización. Respecto a la especialidad de cine, los saberes procedimentales se enuncian en la figura 3.

Figura 3. Saberes procedimentales especialidad de cine.

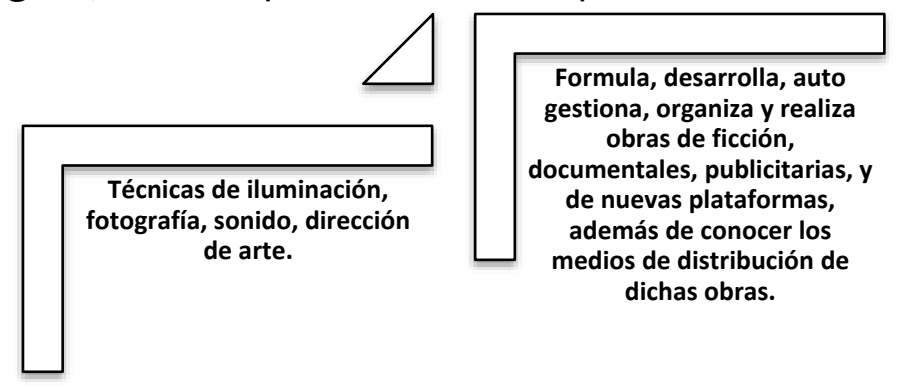

Fuente: Elaboración propia, a partir de uniacc.cl (2018).

En la figura 4, los saberes procedimentales declarados para la especialidad de televisión. 
Figura 4. Saberes procedimentales especialidad de TV.

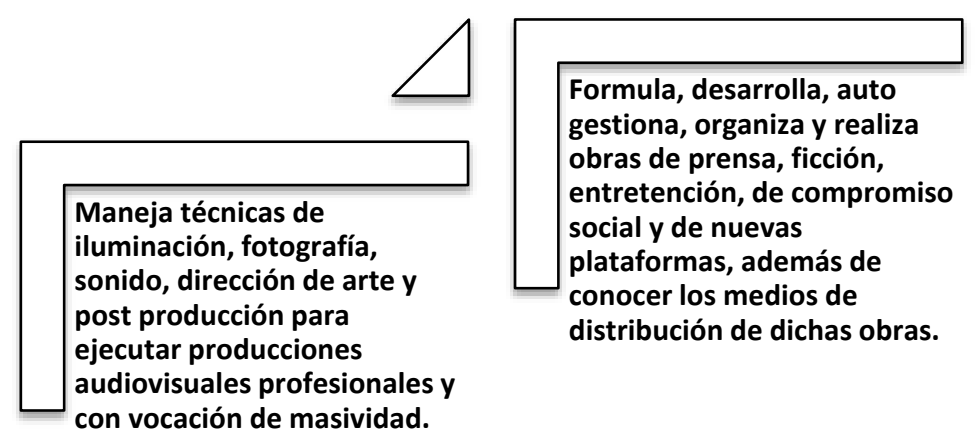

Fuente: Elaboración propia, a partir de uniacc.cl (2018).

El tercer grupo de saberes, como se ha dicho, tiene relación con el sello institucional. Por ende, es donde se esperaría, al menos en el discurso, una especial y destacada mención a los componentes del perfil que "hacen la diferencia" de un/una audiovisualista de UNIACC. Sin embargo, se declaran conductas, habilidades y capacidades que no aparecen sustantivamente lejanas a las esperables de profesionales del área, cualquiera sea el lugar de su formación. Tal vez, ello se deba a la confusión nocional que se evidencia al subyacer la sinonimia entre "actitud" y “comportamiento". La actitud se define “(... ) como una predisposición, aprendida, a valorar o comportarse de una manera favorable o desfavorable hacia una persona, objeto o situación" (Ortego, López, Álvarez, s.f., p. 3). Cabe, por ende, relevar dos aspectos de la noción recién aludida que resultan significativas cuando hablamos de describir actitudes en un perfil de egreso: primero, que las actitudes se aprenden; es decir, "Al ser aprendidas, las actitudes se adquieren y modifican por los mismos procesos que se adquieren y modifican los comportamientos" (Oretgo, et al., p. 3). Segundo, las actitudes no siempre coinciden con el comportamiento, “(...) debido a que sobre las actitudes y el comportamiento inciden variables relacionadas con: la situación, las propias actitudes y los individuos" (Oretgo et al., p. 8). Así, si las actitudes se aprenden, pueden y deben incorporarse de manera explícita al perfil de egreso y, dado que no necesariamente se coligen con la conducta, requieren una enunciación propia y diferenciada de los comportamientos esperados. Como se aprecia en la figura 5, los perfiles de egreso en comento incluyen los mismos "saberes actitudinales" para ambas carreras, y estos, más que actitudinales, predican de “conductuales". A la par, puede leerse en los enunciados de la misma figura 5 una indefinición de lo personal o colectivo como eje de la formación que, probablemente, reafirma la necesidad de explicitar actitudes esperadas en ambos perfiles. 
Figura 5. Saberes actitudinales especialidades de cine y de TV.

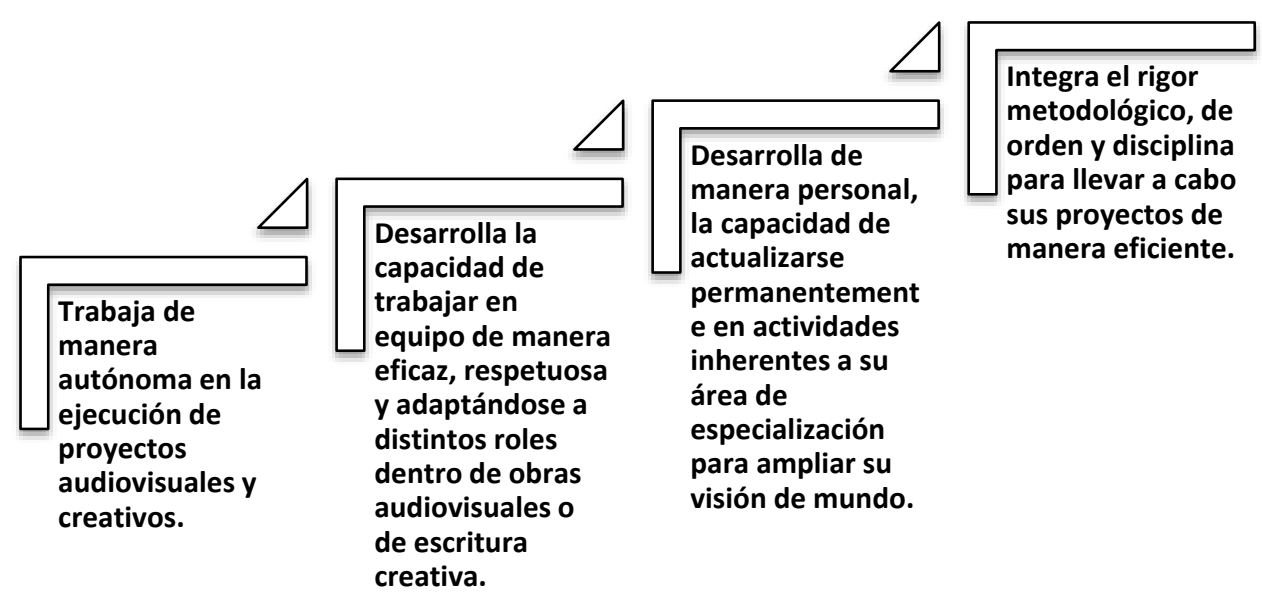

Fuente: Elaboración propia, a partir de uniacc.cl (2018).

Así, el perfil de egreso es un marco y una mirada que la universidad adopta respecto al tipo de educación que entrega, y, por ende, declara el tipo de egresado al que aspira en lo profesional y lo personal (desde lo conceptual, procedimental y actitudinal). Esta mirada debe orientar y articular todo el quehacer al interior de la especialidad (Escuela); por ello, es de capital importancia que esta declaración sea conocida por la totalidad de quienes participan del proyecto educativo: autoridades académicas, directivos, administrativos, docentes y estudiantes.

\section{La Evaluación para el Aprendizaje como paradigma para el aprendizaje significativo.}

La Evaluación para el Aprendizaje es un enfoque de evaluación desarrollado a partir de los años 80 del siglo pasado, y que responde a un cambio paradigmático para entender y llevar a cabo la evaluación de los aprendizajes. Hasta los años 60 y 70, la evaluación fue entendida como fase de producto, como algo que se debía aplicar al final de un proceso, y que estaba destinado solamente a señalar logros o no logros. Un dispositivo cuyo uso era fundamentalmente de control: aprobar, reprobar, promover. Es lamentable verificar que en muchas instituciones de educación esto no ha cambiado en la praxis, no obstante que se declare otra cosa en la teoría. Se trata de un discurso que carece de perlocución (Austin, 2016).

Desde la década de 1960, Bloom, Hastings y Madaus $^{9}$ desarrollan el concepto de

\footnotetext{
9 Handbook on formative and summative evaluation of student learning (1971), publicado en español como Evaluación del aprendizaje (1974, Buenos Aires: Troquel).
} 
evaluación formativa, pero aún con una perspectiva neoconductista: la evaluación de proceso todavía se entiende en el sentido de los instrumentos que se aplican, cada cierto tiempo, para corregir el error y mejorar el proceso. El dispositivo lo conforman esos instrumentos. Así, la evaluación es un hito que ocurre y depende de la generación de instrumentos. "Cuando se concibe la enseñanza como un proceso mecánico de transmisión de conocimientos, linealmente estructurado (sólo puede aprender el alumno, sólo puede aprender del profesor...), la evaluación consistirá en comprobar si, efectivamente, el aprendizaje se ha producido." (Santos, 2003, p. 75). A partir de los años 80 y 90, se desarrolla una línea constructivista en pedagogía y aparece una serie de corrientes con distintos autores en distintos idiomas: “(... ) son diversas literaturas para un mismo cambio paradigmático, cada una con sus énfasis particulares, pero que están en la misma línea de buscar una evaluación más coherente con la mirada constructivista. (Flórez, T., comunicación personal, 31 de mayo de 2018).

La Evaluación para el aprendizaje es parte de la enseñanza significativa, en tanto esta requiere de ciertas dinámicas al interior del aula para que pueda efectivamente producirse "aprendizaje significativo". Entonces, ¿de qué se habla cuando se habla de “Evaluación para el Aprendizaje"?

La experta entrevistada especialmente para esta investigación ${ }^{10}$ clarifica el eje central de dicho enfoque (al cual aludiremos en adelante como EpA): “La evaluación ya no se ve como una serie de creación de instrumentos, que es la visión centrada en la herramienta, sino que la evaluación es una habilidad docente clave." (Flórez, T., comunicación personal, 31 de mayo de 2018).

Se trata, en consecuencia, de un cambio, como se ha mencionado antes, de tipo paradigmático: dejar de lado el "dispositivo" de evaluación aplicado en momentos "solemnes", para evaluar siempre, de manera integrada y constante durante el proceso de aprendizaje-enseñanza. El o la docente abandona la "fecha de la prueba" y evalúa todo el tiempo, de manera formal o informal.

Uno está siempre recogiendo información sobre aprendizaje y retroalimentando, y eventualmente uno quisiera sistematizar eso y para ello puede utilizar un instrumento particular y puede colocar una calificación relacionada con eso. Entonces, el foco de la evaluación para el aprendizaje tiene que ver con aprovechar la información del proceso en función de la mejora del aprendizaje. Es usar la evaluación para mejorar el aprendizaje. (Flórez, T., comunicación personal, 31 de mayo de 2018).

Por lo tanto, el enfoque EpA, más que constituirse solo en un "hacer" diferente, implica modificar el lugar desde el cual el docente trabaja la evaluación.

\footnotetext{
${ }^{10}$ Teresa Flórez, profesora del Departamento de Estudios Pedagógicos de la Facultad de Filosofía y Humanidades de la Universidad de Chile. Doctora en Educación.
} 
Si aquello no ocurre, el proceso educativo se transforma en un mero activismo: las y los estudiantes hacen lo que las y los docentes les indican, pero no saben para qué. $\mathrm{Y}$, en el caso de la educación terciaria, como la mayoría de sus estudiantes viene de culturas escolares donde la nota es el Alfa y el Omega, las y los estudiantes han "aprendido" a cumplir con trabajos y ajustarse a ciertos criterios, pero no saben ni se les ha invitado a reflexionar y establecer previamente de qué manera ese proceso tiene sentido para el ámbito de la reflexión y acción en su vínculo con el mundo, con su contexto. Cómo eso se extrapola para lo que van a hacer/ ser / juzgar / criticar / transformar / crear en el futuro.

Desde el punto de vista de los instrumentos, la experta ya aludida, recomienda el uso de una "rúbrica holística": esta se diferencia de las rúbricas tradicionales o también denominadas "analíticas" que se centran en niveles de logro, porque abordan grandes aprendizajes.

(...) por ejemplo, en el caso del desarrollo de la "creatividad", como este concepto es subjetivo, lo que hacemos no es tratar de objetivarlo, que es una mirada más conductista, sino que hablamos de intersubjetividad. O sea, de llegar a concordar con el otro qué significa ser creativo en este contexto. (Flórez, T., comunicación personal, 31 de mayo de 2018).

En esa intersubjetividad podría, además, situarse una reflexión que responda a la tensión epistemológica que en este informe se ha hecho de "creacióntransformación" como enfoque de los "Aprendizajes Esperados" que declara el Modelo Educativo de UNIACC.

En su exégesis acerca del pensamiento de Karl Popper, en torno al problema de la subjetividad en las ciencias sociales, Harada afirma:

(... ) contra la equivocada idea de algunos teóricos de las ciencias sociales con relación a que, para poder reflejar lo que las cosas son en sí mismas, el científico debe someterse a una especie de 'socioterapia', que lo libere de todos sus prejuicios, ideas previas, intereses, valores, etcétera, en breve, de su subjetividad, Popper nos dice que la objetividad científica no es un estado mental, de neutralidad, de los científicos individuales, sino que es resultado de la crítica intersubjetiva o de la cooperación de muchos sujetos en la tarea de descubrir y corregir sus errores. (2004, p. 11).

En el plano de la evaluación, la noción de Popper no nos lleva a un subjetivismo delirante e impreciso; al revés, permite el mejor aprendizaje, en primer lugar, para despojar a lo "objetivo" de su pedestal de respetable y su consecuente desprecio de lo subjetivo. No hay, siguiendo la cita precedente, posibilidad alguna de lograr aquella "psicoterapia" liberadora; es decir, en lo humano no es posible alcanzar la objetividad; recuérdese el principio de indeterminación de Heisenberg: la relación entre sujeto y objeto del conocimiento también se presenta en las ciencias naturales (Harada, 2004, p. 3). En cambio, es la intersubjetividad la que, en el plano que nos 
ocupa, deviene el mejor recurso para un debate que arribe a los criterios holísticos antes mencionados.

Si desde el principio tenemos criterios claros, donde, por ejemplo, la creatividad es entendida de tal forma, por todos y todas quienes participan, el/la propio/a estudiante se va a fijar que eso esté ocurriendo y los profesores vamos a ir monitoreando y retroalimentando cuando eso no se evidencia en las clases. (Flórez, T., comunicación personal, 31 de mayo de 2018).

Una vez que se han definido el para qué y los criterios, el enfoque EpA propone el diseño de un escenario de evaluación; este no es equivalente a un instrumento de evaluación, sino que expresa el hecho de que en esta mirada didáctica y evaluación se fusionan; es decir, todas las clases o sesiones debieran orientarse a desarrollar los aprendizajes cuya finalidad y criterios fueron aceptados y comprendidos por todos y todas, y ser coherentes con eso.

Una vez que tengo el escenario de evaluación diseñado, voy pensando durante todo ese escenario en el otro componente que es el análisis de evidencia; o sea, tengo que ir mirando todo lo que sucede en la sala de clases, los trabajos que van entregando, a la luz de esos criterios y, al mismo tiempo, retroalimentando. Entonces voy entregando información que permita al otro mejorar durante ese proceso. (Flórez, T., comunicación personal, 31 de mayo de 2018).

La etapa culminante o final de la aplicación del modelo EpA instaura otra sustantiva diferencia con el modelo tradicional: se democratiza el poder en la evaluación; es decir, aquí ya no lo ejerce solo el/la docente, sino que se propone que las y los estudiantes paulatinamente vivan procesos de autoevaluación y coevaluación, que no significa autocalificarse ni cocalificarse.

(...) eso es lo que finalmente busca la evaluación para el aprendizaje, ya que también es una mirada constructivista del aprendizaje, que tiene que ver con generar autonomía, que ya no dependo de que otro me diga que lo estoy haciendo bien, sino que yo, en el futuro, cuando ya tenga que hacer mi propio documental, o lo que sea, ya sé cuándo, por ejemplo, un documental está bien hecho, porque llegué a ese sentido de la autonomía. (Flórez, T., comunicación personal, 31 de mayo de 2018).

En suma, el enfoque EpA es, fundamentalmente, una lógica de trabajo que subvierte la lógica tradicional de la evaluación (dispositivos, instrumentos, momentos, medición, calificación).

Desde luego, un enfoque con los cambios aludidos puede - y es lo más probablegenerar resistencias:

(...) el gran obstáculo tiene que ver con que [el enfoque EpA] no es consistente con el enfoque desde la evaluación externa. O desde los requerimientos administrativos. En el sistema escolar, esos son los grandes 
obstáculos. Otro gran obstáculo, que podría estar presente en la academia universitaria, es el equipo de gestión de la institución que no comparte esto o no lo promueve. Si solo son tres profesores o profesoras haciendo el esfuerzo solos/as, finalmente se cansan y vuelven a lo tradicional, porque es más cómodo que estar yendo contra la corriente. (Flórez, T., comunicación personal, 31 de mayo de 2018).

Lo anterior implica que la mejor forma de implementar el enfoque EpA es generar, primero, un acuerdo entre todo el equipo institucional para trabajar desde esta lógica. $\mathrm{Y}$, cuando ya se trabaja el enfoque y los elementos del enfoque propiamente tal, el momento crítico son los criterios. Esto es, el conflicto cognitivo que están teniendo los participantes cuando cambian la lógica y los criterios: cuando hay que pensar primero en el "para qué” y luego en el "cómo".

\section{Método}

La investigación es exploratoria-descriptiva y la unidad de análisis del estudio fue la Escuela de Comunicación Audiovisual de la Universidad UNIACC. Se utilizaron diferentes informantes clave, la totalidad de ellos y ellas seleccionados/as por conveniencia y como actores y actoras del fenómeno: la directora de la escuela, 9 profesores ( 4 mujeres y 5 hombres) y 47 estudiantes y egresados ( 18 mujeres y 29 hombres). A su vez, se realizó una entrevista a una experta en el enfoque EpA (Evaluación para el Aprendizaje), la doctora en Educación y profesora del Departamento de Estudios Pedagógicos de la Universidad de Chile, Teresa Flórez, quien ha desarrollado investigación y docencia en el ámbito de la evaluación educacional, y específicamente en el enfoque de Evaluación para el Aprendizaje.

El acopio de información se llevó a cabo mediante:

a) la aplicación de 6 grupos de discusión entre el 15 y el 24 de mayo (estudiantes y egresados),

b) encuesta a través de un cuestionario de autoinforme (docentes) y la entrevista individual semiestructurada (directora y experta).

Se elaboraron pautas específicas para experta, autoridad académica, docentes y estudiantes. A su vez, se realizó un análisis crítico de contenido sobre el Modelo Educativo institucional y el respectivo perfil de egreso de las especialidades de Cine y TV. Esto último, con el fin de verificar si se manifiesta la necesidad de adecuar esos instrumentos como parte del proceso que evidencien también necesario los datos por recoger. 


\section{Resultados}

\section{Resultados descriptivos sobre la evaluación.}

Todos los actores (estudiantes, profesores y directivos) coinciden en que el proceso de evaluación es una etapa muy importante dentro del proceso aprendizajeenseñanza: "siempre es necesario que otro te evalúe, para tú entender que adquiriste de verdad el conocimiento" (estudiante). Permiten realizar diagnósticos, medir la comprensión y manejo de contenidos clave, determinar avances a nivel individual y colectivo, dar comentarios y retroalimentación sobre dichos avances y realizar ajustes o actividades remediales al momento de detectar problemas o falencias. También se señala que pueden ser útiles para generar compromiso con las actividades de aprendizaje. "Son útiles para hacer más nítido el criterio con que uno mismo evalúa y sirve para que los estudiantes detecten con claridad sus fortalezas y debilidades, y no sean calificaciones aparentemente arbitrarias" (profesor). "El estudiante necesita saber por qué [lo evalúan], por qué está bien o está mal [lo realizado] y cómo proceder para hacerlo mejor." (directora). El proceso de feedback o retroalimentación de parte del evaluador hacia el evaluado sería sustancial para que el estudiante comprenda los aciertos y errores de su aprendizaje.

Uno de los primeros elementos que se infiere de los discursos que presentan los estudiantes, es que, cuando aluden al concepto de evaluación, inevitablemente este hace referencia a una medición, es decir, evaluar es o conlleva necesariamente una calificación o nota. No se aprecia en el relato la mención de elementos formativos o de diagnóstico. Sin embargo, desde la dirección de la Escuela, se sostiene que evaluar va mucho más allá de calificar. "Es infinitamente más enriquecedor, más complejo, y más respetable cuando realmente esa evaluación sirve para el crecimiento integral [del estudiante]" (directora). Hacia las y los estudiantes, al menos, este discurso no ha permeado y, probablemente, ellas y ellos viven el refuerzo constante de la evaluación como sinónimo de nota.

Las y los estudiantes refieren que durante la carrera han sido expuestos a variados métodos de evaluación (individuales y grupales), enfocados a medir conocimientos (de materia, de aspectos técnicos, de actualidad, controles de lectura, etc.), habilidades y puntos de vista. Entre las principales se encuentran las pruebas escritas con preguntas estandarizadas (de verdadero y falso, de alternativas, mapas conceptuales, etc.), con preguntas de desarrollo, de análisis y de opinión. Los trabajos escritos pueden ser de análisis, informes, ensayos, estudios de caso, entre otros. Las evaluaciones de carácter oral consideran las interrogaciones, presentaciones (pitch, defensa de proyectos, etc.), entre otras. 
Sobre las valoraciones de carácter más práctico están las evaluaciones de participación y desempeño (en clases y en terreno) de aplicación técnica, de recreación (reproducir o imitar un producto audiovisual) y de realización audiovisual (fotografías, reportajes, programas de TV, cortometrajes de ficción, documentales, experimentales, etc.). Para la revisión de trabajos y pruebas se utilizan rúbricas, tablas de cotejo, etc. Los proyectos pueden ser valorados por el profesor responsable, por una comisión evaluadora y en algunos casos se aprecian instancias de evaluación de pares y autoevaluaciones.

Dicho relato de las y los estudiantes es coherente con lo manifestado por las y los docentes como herramientas o técnicas evaluativas que utilizan.

Las y los estudiantes señalan, específicamente sobre el proceso de autoevaluación, que en algunos casos existe, pero es principalmente el productor responsable del equipo de trabajo el que evalúa al resto de los participantes (figura que reviste más características de coevaluador que de autoevaluador).

Sobre la pertinencia de dichas técnicas de evaluación, en su mayoría las y los estudiantes señalan que la carrera debería enfocarse en las de tipo prácticas, ya que señalan que refuerza la forma de "aprender haciendo". Las pruebas con preguntas estandarizadas y aquellas que favorecen el aprendizaje memorístico, salvo casos puntuales (por ejemplo, en algunas asignaturas de carácter más teórico), no les hacen mucho sentido. Les falta, entonces, el "para qué".

En el caso de evaluar trabajos (con el uso de pautas de evaluación o rúbricas) las y los estudiantes señalan que las prácticas docentes son muy variadas, hay docentes muy claros, que trabajan con instrumentos que son socializados con anterioridad y, en cambio, otros/as presentan estrategias ambiguas o simplemente no explican nada, de modo que las y los estudiantes no entienden el porqué de una determinada calificación. A su vez, en este tipo de trabajos, que normalmente son grupales, se plantea la problemática de la evaluación individual versus la grupal (esta última, desde la perspectiva de las y los estudiantes, favorece per se a quienes "no trabajan") y sobre eso se valora que haya más evaluación de proceso que solo la del resultado final. Se señala, por parte de las y los estudiantes, que en la mayoría de las asignaturas que conllevan la elaboración de un producto, la evaluación se enfoca en este último y no en el proceso. Esta versión, sin embargo, contrasta con lo señalado por las y los docentes quienes, en su mayoría, señalan que se evalúa el proceso; algunos/as, que se preocupan tanto del proceso como del producto final, y solo unos pocos reconocen que solo se focalizan en el resultado de la obra "al final esta disciplina audiovisual tiene un rasgo muy decisivamente preponderante en los resultados de por sí. Una película es buena o es mala al margen de los procesos previos. "Las 
excusas no se filman", y eso, a mi parecer, es un elemento formativo en sí" (profesor). Las y los estudiantes sostienen que, al realizar un seguimiento del proceso, se puede hacer un mejor diagnóstico de los avances y de los aprendizajes. En algunos casos se observa que cuando la evaluación del producto final no es satisfactoria, el foco cambia y se observa el proceso, destacando lo aprendido y qué errores no hay que volver a cometer.

El perfil de egreso de la carrera es prácticamente desconocido para las y los estudiantes. La gran mayoría desconoce su existencia y solo un número ínfimo vagamente ha oído hablar de él o vislumbran su sentido. La mayoría de las y los docentes señala conocerlo, pero su aplicación a la asignatura es muy diversa: va desde quienes lo utilizan como un elemento vertebrador de la cátedra, base de los contenidos y orientador de las actividades:

El perfil de egreso lo debo considerar desde la planificación que realizo de mi asignatura. Siempre me pregunto cómo tributa la asignatura, sobre todo cómo los objetivos de aprendizaje responden al perfil. Debo evaluar su correspondencia y gradualidad en la consecución y desarrollo de las habilidades y saberes de los estudiantes (profesor)

Y también hay docentes que no lo utilizan y que, incluso, desconocen el concepto: "Considero que cada curso es diferente y tiene un perfil propio" (otro profesor).

Directivo, docentes y estudiantes advierten las diferencias y dificultades que existen para evaluar un saber o una capacidad en el ámbito de la técnica (que es más "objetivable" con base en ciertos parámetros o indicadores estandarizados fáciles de observar y medir) que en el área artística (que es más subjetiva, ya que el criterio de evaluación difiere de evaluador en evaluador por la experiencia y apreciación que este tenga). Este parece un intríngulis muy difícil de solucionar.

Hay docentes que expresan tener carencias pedagógicas a la hora de crear los instrumentos y/o las actividades con las que se evaluará a las y los estudiantes; por ende, reconocen "no tener las herramientas suficientes para hacerlo" (profesor), "vengo de una formación en que no teníamos una rúbrica clara como estudiante, y cuando comencé como profesor tampoco la tenía” (otro profesor). Sobre dicho proceso de elaborar rúbricas, señalan que las principales dificultades son: definir los parámetros o ítems de valoración en forma objetiva (eliminando la carga subjetiva lo máximo posible) y que estos consideren la totalidad de saberes, habilidades y actitudes necesarias de medir; que su aplicación sea sencilla; que sean fáciles de entender por parte de las y los evaluados; que permitan la corrección oportuna en el 
tiempo establecido; y que exista un adecuado nivel de complejidad, el cual esté balanceando las capacidades del grupo con las exigencias de la asignatura.

Las y los docentes expresan que podrían mejorar los instrumentos, tablas de cotejo y rúbricas que utilizan. Algunos plantean que les gustaría incentivar los procesos de análisis y de reflexión. Otro manifiesta que quisiera que los propios estudiantes se desafiaran a sí mismos, definiendo sus propios objetivos de logro al inicio del semestre.

Me gustaría diseñar un espacio en que los alumnos declaren sus desafíos o espacios de aprendizaje al inicio del semestre, el cual sea evaluado en términos de avance. Una vez logrado, pueden declarar el siguiente desafío. Planeo hacer un piloto en el examen final, solicitando la declaración de un desafío antes de la realización (profesor).

Las y los estudiantes mayoritariamente declaran que no participan en el proceso de elaboración de instrumentos de evaluación (pautas, rúbricas, etc.), las cuales, salvo excepciones, son impuestas por el criterio del profesor: “(... ) pienso que es deber del docente, el cómo evaluar a sus alumnos" (profesor)”. Las y los docentes señalan que comunican sus estrategias de evaluación, y que existen diferentes niveles: desde el que solo comunica el instrumento vía correo electrónico hasta el que realiza ensayos de aplicación, para que el estudiante tome conciencia e interiorice los criterios de la pauta. Algunos/as señalan que "Además de entregarles el instructivo, les doy a conocer previamente la pauta de cotejo o la rúbrica; la explico y en conjunto podemos variar o ajustar algunos aspectos" (otro profesor). Con esto, por lo tanto, se da pie a posibles adecuaciones del instrumento. Otros y otras docentes, en el transcurso del presente estudio, tomaron conciencia de la posibilidad: "No descarto involucrar a los alumnos en este proceso en el futuro" (un tercer profesor). El estudiantado señala que la oportunidad de poder participar en la elaboración de una rúbrica o pauta de evaluación permitiría una mayor comprensión de los aspectos que luego serán valorados como positivos (logrado) o negativos (no logrado).

A partir del relato de las y los docentes, se aprecia que existe diversidad en la forma que cada uno de ellos realiza el proceso de retroalimentación sobre las evaluaciones y el nivel de detalle de ese feedback. Existen quienes lo hacen de forma directa, hablando y entregando comentarios; otros/as prefieren dejarlo por escrito (v.gr., documento Word, Excel) y entregarlo por correo o a través de la plataforma del curso en e-Campus. Varios/as estudiantes señalan expresamente que prefieren el feedback oral y directo por sobre el escrito enviado por correo. Hay docentes que crean los espacios de discusión general, dando oportunidad de participación a los estudiantes. 
El estudiantado considera que hay profesores muy buenos y otros muy malos. Se señala que algunos docentes imponen su poder diciendo cosas como "Aquí hablo lo que yo quiera... tengo cátedra libre, así que puedo hacer lo que yo quiera" (ejemplo de un estudiante) y otros tipos de violencia (sutiles o directos) atacando la autoestima y denigrando al educando "eres penca, cómo no se saben esto, esto es lo mínimo que debería saber un ser humano" (otro ejemplo señalado por un estudiante). Algunos y algunas estudiantes señalan que hay profesores que aplican las mismas evaluaciones año a año, que no hay renovación de los instrumentos y que tampoco estos se ajustan a las necesidades particulares de cada grupo de estudiantes.

La mayoría del estudiantado siente que las evaluaciones docentes no tienen un eco en el posterior trabajo en la escuela (trabajo correctivo), ya que se ve que los malos profesores y sus malas prácticas se perpetúan en el tiempo, a pesar de una desfavorable evaluación docente. En forma general, se señala que la evaluación docente, a pesar de que les ocupa bastante tiempo, se realiza en conciencia, sin embargo, algunos reconocen que esta se hace de forma rápida y sin mucha atención para poder acceder al conocimiento de sus notas.

Ciertos/as estudiantes señalan que es patente que en algunos cursos los docentes están sobrepasados por las condiciones en que deben realizar las clases, en especial en las de características más prácticas (realización, fotografía, posproducción, por ejemplo) donde se llevan a cabo ejercicios durante la clase. Se plantea como solución el que las y los docentes cuenten con un ayudante (o varios, según el caso) para apoyar las labores educativas y permitir que este equipo docente tenga el tiempo para realizar un efectivo feedback evaluativo. Hay docentes que señalan que deben invertir mucho tiempo fuera del aula de clase para corregir y evaluar trabajos, instancias que no son consideradas a la hora de establecer las remuneraciones. En la misma línea, también se valora cuando los cursos son pequeños, puesto que se crea una mejor intimidad, se fomenta mejor el diálogo para discutir sobre los trabajos y recibir una retroalimentación. También se señala la relevancia de entregar oportunamente los resultados, de modo que quien estudia tenga el tiempo de comprender cuáles son sus fortalezas y en qué debe mejorar.

En algunos casos, hay asignaturas donde se les exige a las y los estudiantes saberes que aún no han abordado, dándolos, sin embargo, por "sabidos", lo que dificulta los procesos de aprendizaje. Dicho resultado es un indicativo de falencias en las etapas de diagnóstico "... nosotros tenemos que adaptarnos y hacernos cargo de los perfiles de ingreso" (directora) y del estado de avance de nuestro estudiantado.

Las y los estudiantes indican que hay asignaturas que tienen poco tiempo para 
enseñar todo lo que necesitan (v.gr., en televisión, el uso técnico del estudio y del móvil), y requerirían más semestres. En estas asignaturas, por ello, se aprenden las cosas mecánicamente, sin entender mucho el porqué de los procedimientos. A su vez, en ese tipo de asignaturas, por esta falta de tiempo, se da el fenómeno de que muchos se especializan en un área específica que aprenden a hacerla bien y se prefiere seguir realizando lo mismo para adquirir experiencia y no arriesgar una mala nota en otra tarea que no se sabe ejecutar con tanto éxito. Por el contrario, en otras asignaturas sobra el tiempo. Lo mismo ocurre con el equilibrio de dificultades, hay ramos muy fáciles y otros que son casi imposibles "es que hay que dar la vida..." (estudiante).

El discurso de estudiantes y docentes señala una preferencia por evaluaciones más integradas entre las diferentes asignaturas (intercátedra) para focalizar el trabajo en menos cosas. "... juntar en un examen final la gran mayoría de ramos. Por ejemplo, tenemos dirección de actores, foto, sonido, producción, y todos esos perfectamente pueden hacer un examen... [y] obviamente va a quedar más lindo en sonido, más lindo en foto" (estudiante). "Me gustaría trabajar más en conjunto con otros ramos y docentes, creo que hay semestres que al menos en la carrera y ramos que yo imparto son más efectivos si se hace trabajo conjunto y no de forma individual" (profesor), "se deberían establecer procesos de evaluación final semestral (exámenes) transversales, que permitan al estudiante comprender por qué la malla presenta esas asignaturas y cómo estas, en un todo, contribuyen al perfil de egreso laboral en dicho semestre" (otro profesor). Pero la evaluación debe ser individual en función de las responsabilidades (roles) de cada estudiante, sostienen otros docentes.

Se observa que para aquellos/as de las y los estudiantes que tienen una beca, la cual depende de los resultados académicos para mantenerla vigente, la calificación refuerza su función más bien utilitaria. Se desprende de su discurso que dichos estudiantes están más preocupados de mantener la calificación para conservar la beca que de aprovecharla como una referencia de su propio aprendizaje. En este caso, sin perjuicio de la necesidad de establecer un mínimo indicador de logro en relación con la beca, cabe comentar que dicho uso incrementa el rol utilitario de la calificación, en desmedro de la focalización esperada por parte de las y los estudiantes en sus propios aprendizajes.

\section{Resultados descriptivos sobre otros tópicos.}

En el proceso de recolección de información, a partir del relato de los informantes clave como estudiantes y docentes, aparecieron una serie de problemáticas que, si bien no se relacionan directamente con el objeto de estudio (los métodos y procesos 
de evaluación), sí se consideraron relevantes de rescatar, pues la solución de los mismos podría significar mejoras en el plan de estudio de las especialidades de Cine y Televisión.

Se valora el plan común, pero hay quienes plantean que este debería durar un año, tiempo suficiente para conocer la carrera a nivel general y poder optar a una mayor especialización (guion, arte, foto, post, sonido, etc.). "el que mucho abarca, poco aprieta. Yo creo que, para generar buenos profesionales es necesario especialistas" (estudiante). En la misma línea pero en sentido opuesto, se considera, por parte de las y los estudiantes, que la carrera es muy cerrada, ellas y ellos quisieran poder tener la posibilidad de elegir algunos electivos en otros temas, para, sobre la base de sus propios gustos e intereses, aumentar los conocimientos en estas áreas específicas del saber.

En el relato general de las y los estudiantes se observa que tienen una mirada utilitaria de las cosas y de su proceso de aprendizaje; por ejemplo, no están dispuestos a estudiar y a realizar trabajos prácticos a base del análisis de otras películas (estudios de caso), quieren aprender arte o cualquier otra área en la práctica, haciendo su propia película.

Se señala, por parte de las y los estudiantes, que faltan incentivos y canales para exhibir los trabajos, se subraya que se podrían utilizar instancias como el canal de TV o la radio UNIACC para darle salida a los proyectos realizados en las asignaturas.

Se plantea (estudiantes) que fue un error haber eliminado el inglés como una asignatura obligatoria dentro de la malla, por la importancia que tiene dicho saber en el desarrollo profesional con características cada vez más internacional.

Por parte de las y los estudiantes se desprenden quejas hacia la mantención de los equipos y se sienten menospreciados/as con respecto a otras carreras como periodismo y danza. Las y los profesores también señalan mayoritariamente que hay carencias de infraestructura.

Se plantea, por parte de las y los estudiantes, que no existe un criterio armónico con respecto a la asistencia a clases. Para algunos profesores, es algo más laxo y otros son más exigentes. Hay estudiantes que señalan que la asistencia es un arma del profesor para castigar a los estudiantes a los que "les tienen mala". 


\section{Discusión y conclusiones}

El modelo educativo de universidad UNIACC no ofrece toda la claridad conceptual que sería deseable para enmarcar en lo epistemológico, didáctico y en la aplicación práctica un enfoque evaluativo que tribute al aprendizaje significativo.

Por su parte, los perfiles de egresos de las carreras consideradas para esta investigación dan cuenta de dos características preocupantes en lo que a efectos en la evaluación respecta. En primer término, su casi unánime desconocimiento por parte de las y los estudiantes y su disímil consideración en el caso de las y los docentes encuestados. En segundo lugar, y sobre su contenido enunciativo, destacan la focalización en la praxis, la discutible evidencia de un sello propio y la indiferenciación de actitudes y comportamientos.

La eventual y, desde luego, paulatina aplicación del enfoque de evaluación educativa denominado Evaluación para el Aprendizaje (EpA) representa una alternativa factible y que podría marcar un punto de inflexión hacia la mejora de las prácticas evaluativas, especialmente, en lo que respecta a los productos audiovisuales que son de la esencia de la mayoría de las asignaturas de ambas carreras y que — como se ha dichoaparecen también mayoritariamente en los perfiles de egreso.

De hecho, la información recogida da cuenta de la necesidad de generar un cambio de paradigma, una transformación actitudinal y de comportamiento en todos y todas quienes participan del proceso formativo en la institución. La evaluación no puede seguir siendo percibida como una herramienta represiva y castigadora, o bien, que solo mide los logros en un momento determinado; hay que conceptualizarla hacia las potencialidades y los aprendizajes significativos que puedan desarrollar las y los estudiantes, en los cuales el error también cumple un rol fundamental. Anijovich y González (2011) señalan, al respecto, que hay errores solo ligados al azar o la distracción, sobre los cuales no cabe sino una acción correctiva, pero existen los que esos autores llaman "errores inteligentes" y que se caracterizan por requerir algún tipo de conocimiento; por ejemplo, decir "cabió" en lugar de “cupo", implica que se sabe la conjugación regular y su aplicación, pero que falta proponer actividades que le permitan al o a la estudiante "construir" la noción y aplicación de los verbos irregulares. Así, desde el enfoque constructivista, el error implica:

- Aceptar que este es inevitable y comprender que negarlo o pasarlo por alto no implica eliminarlo.

- Asumir que es necesario reflexionar junto con el sujeto que comete el error para ayudar, en primera instancia, a tomar conciencia de él para luego superarlo, lo que significará lograr un aprendizaje más complejo y profundo.

- Investigar cuáles son los errores sistemáticos de las disciplinas que enseñamos para proponer situaciones que permitan explicitarlos y tratarlos (Anijovich y González, 2011, p. 127). 
A través del relato de los diferentes informantes, se aprecia que a lo largo de la carrera se utiliza una gran variedad de técnicas e instancias de evaluación; sin embargo, la pertinencia de estos procedimientos no siempre es significativa para los estudiantes. Un elemento fundamental dentro del proceso de aprendizaje es que quien aprende perciba que el procedimiento evaluativo es útil y necesario para dicho proceso. Si la o el estudiante no aprecia la evaluación, no siente que obtuvo un beneficio (v.gr., descubrir los aciertos y las debilidades o errores, saber cómo potenciar los éxitos y corregir las equivocaciones), difícilmente la instancia tendrá un valor formativo. Para favorecer dicho proceso se recomienda ir más allá de una buena explicación de los instrumentos evaluativos y hacer parte a quien estudia de su proceso de evaluación de aprendizajes, dándole el espacio de participación no solo en la elaboración de los instrumentos y las pautas de valoración, sino que siendo parte en la discusión y construcción de las actividades que se desarrollarán para fomentar los aprendizajes, instancias que pueden motivar procesos reflexivos de lucidez conceptual, entendimiento y son altamente efectivos para lograr la autonomía de quien estudia. Dicho proceso sería especialmente útil en la elaboración de materiales que puedan servir para evaluar trabajos o actividades de carácter artístico, tales como pautas de cotejo, escalas de apreciación y rúbricas, por ejemplo, a través de dinámicas de intersubjetivación, ya que no es posible la objetivación. Por lo mismo, el modelo EpA promueve un tipo de evaluación holística, centrada en todo el proceso (en todo momento a lo largo de ello) y no en el resultado final. Una significativa evaluación no solo depende de las herramientas o instrumentos utilizados, también es necesario que el evaluador realice una adecuada retroalimentación, la cual debe ser sistemática y oportuna a cada momento. Un número mayoritario de los y las estudiantes participantes en este estudio señalaron que prefieren la retroalimentación realizada en directo, en forma presencial, donde el o la docente explica claramente los resultados del escenario de evaluación (el eje no es el instrumento, sino el avance hacia el para qué definido y compartido en el inicio).

De igual modo, existe diversidad de estudiantes y preferencias de cada uno/a de ellos y ellas hacia determinadas formas de evaluar. Para evitar que algunos o algunas estudiantes perciban grados de discriminación hacia un tipo de evaluación que, por sus características, ellas y ellos consideran que los perjudican (por ejemplo: alguien que por su timidez cree que las interrogaciones orales son muy desfavorables), es bueno que al interior de una misma asignatura los diseños de escenarios de evaluación supongan distintas formas para dar cuenta del aprendizaje.

La rúbrica holística (propia del enfoque EpA) debe centrar sus esfuerzos en empoderar y darle autonomía a las y los estudiantes. Si el estudiante es capaz de visualizar autónomamente en qué se equivoca, podrá autoajustar su trabajo, enmendar los errores y conseguir los objetivos que en conjunto con el profesor 
acordaron. En este marco, se consignan en la tabla 3 los siguientes indicadores que se señalan en la literatura especializada en EpA como criterios para el docente cuando debe elaborar este tipo de rúbricas:

Tabla 3. Criterios para validar rúbricas.

\begin{tabular}{|c|c|c|}
\hline ASPECTO & PREGUNTAS SOBRE LA EVALUACIÓN & $\begin{array}{l}\text { POTENCIALES AMENAZAS PARA LA } \\
\text { VALIDEZ }\end{array}$ \\
\hline Propósitos & $\begin{array}{l}\text { ¿Cuál es el propósito de esta } \\
\text { evaluación? } \\
\text { ¿Hay múltiples propósitos? }\end{array}$ & $\begin{array}{l}\text { Falta de claridad; propósitos que } \\
\text { compiten entre sí, propósitos } \\
\text { inalcanzables... }\end{array}$ \\
\hline \multirow[t]{2}{*}{$\begin{array}{l}\text { Validez de constructo y } \\
\text { adecuación al propósito }\end{array}$} & ¿Qué se evalúa? & $\begin{array}{l}\text { Constructo poco claro; constructo } \\
\text { discutible o que produce disenso. }\end{array}$ \\
\hline & ¿Hace la evaluación lo que dice hacer? & $\begin{array}{l}\text { Muestreo inadecuado del } \\
\text { constructo o dominio (sub- } \\
\text { representación del constructo); } \\
\text { muestreo de otros constructos } \\
\text { (irrelevancia al constructo). }\end{array}$ \\
\hline \multirow[t]{2}{*}{ Confiabilidad } & $\begin{array}{l}\text { ¿Qué tan confiable es el sistema de } \\
\text { evaluación? }\end{array}$ & $\begin{array}{l}\text { Violaciones de seguridad; } \\
\text { administración no consistente del } \\
\text { test; modificaciones inapropiadas; } \\
\text { limitaciones de tiempo; } \\
\text { confiabilidad del examinador }\end{array}$ \\
\hline & $\begin{array}{l}\text { ¿Qué tan defendibles son los } \\
\text { resultados? }\end{array}$ & $\begin{array}{l}\text { Esquemas de puntuación } \\
\text { inconsistentes; puntuación poco } \\
\text { confiable; captura y agregación de } \\
\text { puntajes poco confiable; datos } \\
\text { insuficientes para la toma de } \\
\text { decisiones; pesos inapropiados; } \\
\text { procesos de establecimiento de } \\
\text { niveles inconsistente; referencia } \\
\text { limitada a estándares previamente } \\
\text { definidos. }\end{array}$ \\
\hline $\begin{array}{l}\text { Interpretación de } \\
\text { resultados }\end{array}$ & $\begin{array}{l}\text { ¿Qué tan confiables son los resultados } \\
\text { en relación con los propósitos para los } \\
\text { cuales son utilizados? }\end{array}$ & $\begin{array}{l}\text { Confiabilidad limitada de resultados } \\
\text { individuales; clasificación errónea; } \\
\text { inequidad; sesgo; falta de } \\
\text { comparabilidad; consistencia de año } \\
\text { a año; interpretaciones simplistas, } \\
\text { poco precisas de los resultados } \\
\text { agregados. }\end{array}$ \\
\hline \multirow[t]{2}{*}{$\begin{array}{l}\text { Impacto } \\
\text { Consecuencias }\end{array}$} & $\begin{array}{l}\text { ¿Qué tan efectivamente se han } \\
\text { cumplido los propósitos? }\end{array}$ & Confianza limitada en los resultados. \\
\hline & $\begin{array}{l}\text { ¿Hubo consecuencias no } \\
\text { intencionadas? }\end{array}$ & $\begin{array}{l}\text { Interpretaciones discutibles de los } \\
\text { resultados; decisiones inapropiadas } \\
\text { sobre la base de los resultados; } \\
\text { impacto negativo en la enseñanza y } \\
\text { el aprendizaje. }\end{array}$ \\
\hline
\end{tabular}

Fuente: elaboración propia, a partir de pecuchile.cl, 2016. 
La consideración de las preguntas incluidas en la tabla 3 permite al docente producir una rúbrica holística con la mayor certeza de que ella sirve a los propósitos de la evaluación de los aprendizajes. Desde luego, esta puede o no generar algún tipo de calificación, pues — como se ha mencionado en este informe- la EpA no supone necesariamente el subproducto de una nota.

Según Susan Brookhart (2013, p. 29), los criterios requeridos en la elaboración de rúbricas debieran considerar las características que se describen en la tabla 4.

Tabla 4. Criterios para elaborar rúbricas.

\begin{tabular}{ll}
\hline Apropiados & $\begin{array}{l}\text { Representan un aspecto del objetivo de aprendizaje que se espera } \\
\text { aprendan los estudiantes. }\end{array}$ \\
\hline Definibles/comprensibles & $\begin{array}{l}\text { Presentan un significado claro y entendible por docentes y } \\
\text { estudiantes. }\end{array}$ \\
\hline Observables & $\begin{array}{l}\text { Cada criterio describe una cualidad en el desempeño que puede } \\
\text { percibirse por alguien más que la persona que está realizando la labor. }\end{array}$ \\
\hline Diferenciados & $\begin{array}{l}\text { Cada criterio identifica un aspecto distinto del aprendizaje o del } \\
\text { resultado que se espera que el desempeño evalúe }\end{array}$ \\
\hline Completos & $\begin{array}{l}\text { El conjunto de criterios describen la totalidad del aprendizaje que el } \\
\text { desempeño manifiesta. }\end{array}$ \\
\hline Establecen continuo de calidad & $\begin{array}{l}\text { Cada criterio puede ser descrito en términos de calidad en un continuo } \\
\text { de desempeño "alto" y “bajo". }\end{array}$ \\
\hline
\end{tabular}

Fuente: Brookhart (2013, p. 29)

Una vez definidos y descritos los criterios que incluirá la evaluación, corresponde tener presente algunas recomendaciones para su concreción formal.

El número de niveles que se describa deberá corresponder a la cantidad de niveles significativos de calidad de desempeño que se puedan discriminar. Cada uno debiera reflejar lo observable del trabajo de las y los estudiantes; es decir, no implica un juicio de calidad sobre el trabajo. Se puede describir de manera específica o genérica cada tarea evaluada. Es recomendable describir el nivel competente que se espera que la mayoría de las y los estudiantes alcancen, y luego los otros niveles en un continuo. Es decir, diferenciar la calidad de un nivel a otro con pequeñas variaciones $y$, al mismo tiempo, ejemplificar lo que se espera en cuanto a logro en cada nivel. Describir niveles no es lo mismo que hacer una lista de instrucciones; dicha descripción debe permitir múltiples vías de solución para una tarea, puesto que un exceso de detalles podría alentar un aprendizaje superficial, es decir, las y los estudiantes se limiten a seguir las 
instrucciones (Brookhart, 2013).

Respecto a la escala, se sugiere que ella tenga entre 4 a 5 niveles, ya que menos alternativas no permiten diferenciar correctamente entre los que lo se hace bien y mal, y una mayor cantidad de grados superan la capacidad que la mayoría tiene para discriminar entre ellos (Leclercq y Cabrera, 2014). Por su parte, Brookhart (2013) sugiere cuatro niveles, por ejemplo: avanzado, proficiencia, básico y bajo lo básico. Sin embargo, en función de lo que queremos evaluar, podemos ajustar la cantidad de niveles. Por ejemplo, un trabajo sencillo requerirá menos criterios que uno complejo. Por naturaleza, las personas tienden a evaluar centradamente, razón por la cual es recomendable que la escala tenga niveles pares (obliga a discriminar si el logro evaluado está por sobre o bajo el punto medio).

Asimismo, es recomendable, desde el punto de vista formal, que la distribución de los niveles de logros (columnas), se presenten de izquierda a derecha de mayor a menor logro, enfatizando de este modo los juicios positivos del aspecto evaluado.

En suma, tanto de la literatura consultada, así como del análisis de los documentos institucionales pertinentes $y$, especialmente, de la información recogida en la aplicación de grupos de discusión, encuesta y entrevistas, se puede concluir que la evaluación es un tópico que requiere procesos de reflexión crítica en el quehacer académico de la universidad UNIACC, tanto a nivel directivo como de estudiantes y de docentes. Asimismo, puede sugerirse el enfoque EpA como una modalidad que, por sus características, da respuesta a buena parte de las necesidades detectadas en el estudio. Por ejemplo, un congreso, seminario o jornada que reúna a la totalidad de los actores del proceso (estudiantes inclusive) con expertos y expertas en la materia, podría sugerirse como un buen punto de partida para asumir la necesidad de optimizar este tópico siempre decisivo en cualquier proceso formativo.

\section{Referencias}

Anijovich, R. y González, C. (2011). Evaluar para aprender. Buenos Aires: Aique Grupo Editor.

Austin, J. (2016). Cómo hacer cosas con palabras. Barcelona: Paidós.

Bloom, B., Hastings, J. y Madaus, G. (1974). Evaluación del aprendizaje. Buenos Aires: Troquel.

Brookhart, S. (2013). What Are Rubrics and Why Are They Important? En How to create and use rubrics for formative assessment and grading. Alexandria: ASCD.

Drago, C. (2017). Manual de apoyo docente. Evaluación para el aprendizaje. Santiago: Universidad Central de Chile. Recuperado de 
http://www.ucentral.cl/prontus_ucentral2012/site/artic/20170830/asocfile/201708 30100642/manual_evaluacion.pdf

Harada, E. (2004). Karl Popper y el problema de la objetividad de las ciencias sociales. Revista Magister, 120, 5-12. Ciudad de México: Universidad Nacional Autónoma.

Krause, M. (1995). La investigación cualitativa: un campo de posibilidades y desafíos. Revista temas de educación, 7, 19-40.

Leclercq, D. y Cabrera, A. (2014). Capítulo VI: La calificación subjetiva de los desempeños complejos. En D. Leclercq y A. Cabrera (Eds), Ideas e innovaciones en dispositivos de evaluación de los aprendizajes en la enseñanza Superior (pp.103-127). Santiago de Chile: Editorial Universitaria.

Lemaitre, M. (s.f.). Perfiles de egreso. Recuperado de https://cinda.cl/publicaciones-yarchivos/archivos-y-documentos/

Lethem (2008). Contra la originalidad. Ciudad de México: Tumbona Ediciones.

Morin, E. (2000). Los siete saberes necesarios para la educación del futuro. París: UNESCO.

Morin, E. (2011). Introducción al pensamiento complejo. Barcelona: Gedisa.

Saberes Docentes: Centro de Estudios y Desarrollo de Educación Continua para el Magisterio (2016). Elaboración de criterios, escenarios de evaluación y rúbricas para el aprendizaje. Recuperado de www.pecuchile.cl

Pérez Serrano, J. (1994). Investigación cualitativa. Retos e interrogantes. Técnicas y análisis de datos. Tomo II. Ed. La Muralla S.A.: Madrid.

Santos, M. (2003). Dime cómo evalúas y te diré qué tipo de profesional y de persona eres. Enfoques educacionales 5 (1), 69-80. Málaga: Universidad de Málaga.

Taylor, S. J. y Bogdan, R. (1992). Introducción a los medios cualitativos de investigación: la búsqueda de significados. Paidós: Barcelona.

Universidad de Artes, Ciencias y Comunicación (2015). En Proyecto Educativo. Recuperado de www.uniacc.cl

Universidad de Artes, Ciencias y Comunicación (2016). En Modelo Educativo. Recuperado de www.uniacc.cl

Universidad de Artes, Ciencias y Comunicación (2018). En Perfiles de egreso. Recuperado de www.uniacc.l 
Christian A. Reyes Gavilán (investigador responsable)

Doctor en Comunicación por la Universidad de Ciencias, Artes y Comunicación (UNIACC), licenciado en Letras y profesor de Castellano por la Pontificia Universidad Católica de Chile. Académico de modalidades presencial, semipresencial y en línea. Diseñador instruccional de programas educativos digitales. Más de una década de experiencia en docencia de cátedras en los ámbitos de semiología audiovisual, comunicación social, análisis de audiencias, metodología de la investigación, ética profesional, filosofía y literatura, comunicación política, clima y convivencia escolar, formación en ciudadanía y derechos humanos. Profesor guía y metodológico de proyectos de título y grados académicos. Actualmente se desempeña como director académico de la Universidad Abierta de Recoleta (UAR), y en proyectos específicos de docencia y asesoría metodológica y pedagógica en las universidades de Chile y UNIACC.

\section{Alexander Pszczolkowski Parraguez (coinvestigador).}

Doctor en Comunicación Audiovisual por la Universidad de Salamanca, España. Licenciado en Artes y Ciencias de la Comunicación de la Universidad UNIACC y Comunicador Audiovisual del Instituto Profesional IACC. En la actualidad, pertenece a la planta académica de la Escuela de Cine de la Universidad Mayor, y realiza docencia en la Universidad Central de Chile y en la Universidad UNIACC. Académico con más de quince años de experiencia en los campos de teoría de la comunicación, lenguaje audiovisual, talleres de realización de cine y televisión, apreciación cinematográfica, metodología de la investigación, seminarios de título e historia del arte. Profesor guía de proyectos de título, memorias y tesis de grado.

Javier Muñoz Percherón (ayudante de investigación).

Comunicador Audiovisual con mención en guiones para cine y televisión por la Universidad de Artes, Ciencias y Comunicación (UNIACC). Siete años de experiencia en escritura cinematográfica y otros medios, incluyendo una campaña presidencial para Alfredo Sfeir. Estrenos en los dos festivales más importantes de Chile, con su primer largometraje, El Último Lonco en SANFIC, y con el tercero, La Isla de los Pingüinos en FICV, sumado a estrenos en el plano internacional como el Festival Internacional de Cine de Guadalajara (México), así como en cines comerciales en Chile y en el extranjero. 